\title{
Shape Accel Arrays - comparative performance in a mining application
}

\author{
GE Swarbrick Pells Sullivan Meynink, Australia \\ SJ Clarke Pells Sullivan Meynink, Australia
}

\begin{abstract}
Shape Accel Arrays (SAAs) are being increasingly used to monitor in-ground movements at a relatively high frequency of interrogation (typically minutes). While there are significant benefits in the use of SAAs over traditional manually operated inclinometers, there remain a number of potential issues and drawbacks.

Recently, an SAA was installed alongside a standard manual inclinometer installation to monitor ground movement below critical infrastructure. The instruments were used to monitor potential movements due to nearby mining.

Results from both systems have been compared on a monthly basis for the past two years. During this time a number of issues were observed within the SAA results, these being false deformation, instrument drift and temperature effects.

This paper describes the design, construction and monitoring of the instruments, issues encountered, and the methods employed to rectify or minimise the impact of these shortcomings. The instrument continues to provide necessary advance warning on mining induced movements.
\end{abstract}

\section{Introduction}

The SAA is a relatively new device designed to report its shape in three dimensions (3D) based on measurements of the gravitational field. The technology was pioneered for use in geotechnical applications by Measurand, a company based in Canada. Measurand are the major supplier of SAA systems around the world.

The twin bridges over the Nepean River at Douglas Park were constructed in 1980 as part of an extension of the Hume Highway from Campbelltown to Yanderra south of Sydney. Each carriageway is supported by a six deck spans simply supported on five piers and the end abutments. Piers are around $50 \mathrm{~m}$ tall ranging in height from 10 to $55 \mathrm{~m}$ and spans range from $25 \mathrm{~m}$ near the abutments to $50 \mathrm{~m}$. The deck is up to $68 \mathrm{~m}$ above the valley floor.

The Bridges were not originally designed to accommodate subsidence but in the later stages of design, hinges were introduced in the decks, which made it possible for the Bridges to tolerate some mining induced movements. However, the convention at the time was that the bridges lay outside of the expected area of influence (termed the angle of draw) and therefore there was no expectation of any potential mining induced movements.

During extraction of Tower Colliery longwalls 16 and 17 in 1999 and 2000 total horizontal movements of 30 to $70 \mathrm{~mm}$ were observed in the Douglas Park twin bridges located about $570 \mathrm{~m}$ away. These movements prompted a review of potential movements due to future mining, what monitoring systems would be appropriate and assessments of geological conditions prior to any subsequent mining the area. More information on the impacts of Tower longwalls on the Douglas Park bridges may be found in Hebblewhite (2001). 


\section{Background}

The SAA technology was initially developed to record rapid human movements in 3D for use in a variety of applications, such as animation. The device is thus lightweight, flexible and be able to respond rapidly. Measurand redefined the application of such devices as a linear array of sensors buried in the ground that could be interrogated remotely and used to assess subsurface movement.

The essential components of SAAs, Figure 1, are:

1. A linear array of segments connected by flexible jointing.

2. Accelerometers (typically three) mounted within each segment to measure components of gravitational acceleration in orthogonal directions.

3. A system of interrogation, data compilation and interpretation to determine the shape of the array (typically in 3D).

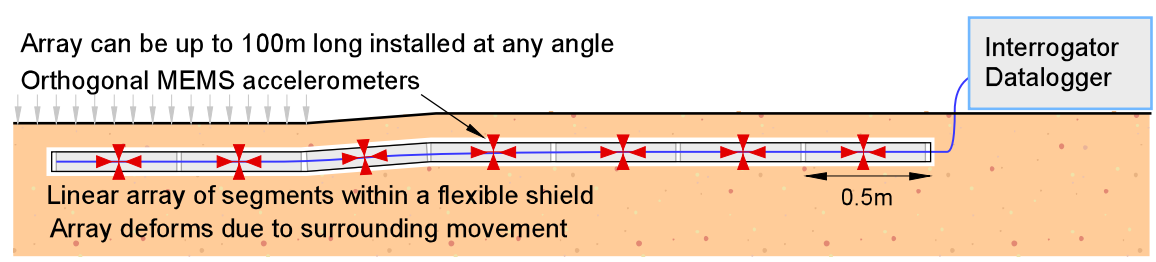

\section{Figure 1 Schematic of an installed SAA}

The SAA uses micro electromechanical sensors (MEMS) to measure changes in the apparent gravitational field due to movement of the array. MEMS devices measure the response of a small mass moving in response to gravity against a high-resolution micro mechanical spring. Changes in movement of the mass are related to changes in gravity as the sensor rotates about its various axes. This tilt is converted to a movement based on the length of each SAA segment. The manufacturer indicates a resolution of $1.5 \mathrm{~mm}$ over $32 \mathrm{~m}$ length (for $305 \mathrm{~mm}$ long segments installed vertically).

SAAs can also include temperature and magnetometer sensors.

The authors are most familiar with the Measurand SAA device. These devices employ:

- Linear segments $500 \mathrm{~mm}$ long, each containing a MEMS acceleration sensor.

- A polyethylene membrane to house the segments and provide protection and structural support, which is $24 \mathrm{~mm}$ diameter at the joints and $22 \mathrm{~mm}$ diameter elsewhere.

- A temperature sensor included in every eighth segment.

- A serial interrogator for data collection for upload to a computer or storage by data logger.

- Optional magnetometer sensors used to measure orientation of the array.

Measurand SAAs do not rely on precise alignment of MEMS sensors at the time of assembly. Instead, sensors are assembled with essentially random orientations of the local $\mathrm{X}$ and $\mathrm{Y}$ axes. The $\mathrm{Z}$ axes are aligned with each segment.

Calibration of the array is undertaken in the factory by placing the array on a straight level surface. The measured response is then reconciled against the physical geometry of the array and correction factors for each segment calculated. From these readings a set of calibration constants is generated to correct the acceleration read by the randomly oriented MEMS sensors to $X$ and $Y$ axes, which are common to the entire array (i.e. global axes). In this manner, every SAA has a unique set of calibration constants which correspond to the original assembly of the array.

This approach has the following advantages:

- Installation can be undertaken quickly. 
- Calibration constants provide a means of accurately 'aligning' the instrument.

The main disadvantage of this approach is that accuracy will vary from sensor to sensor within the array due to the differing orientation of the accelerometers. This is because MEMS devices do not exhibit linear sensitivity across their measurement range.

Overall the main advantages of SAAs are:

- Full 3D measurement of movement.

- Ability to be automatically read and trigger alarms.

- Real-time measurement (e.g. typically 10 to $20 \mathrm{~min}$ cycle time to monitor a $50 \mathrm{~m}$ array).

- Orientation can be vertical, horizontal, inclined or other shapes.

- Waterproof and relatively robust.

- May be installed in boreholes, along pipelines or within structures.

- Low operating cost compared to manual inclinometers (depending on monitoring frequency).

The ability to measure full 3D movement is contingent on a couple of key assumptions:

- Length of segments remains constant.

- No axial rotation (twist) occurs along the array.

The second assumption was violated in the Douglas Park installation, as discussed further below.

The main disadvantages are:

- Greater equipment cost per hole compared to manual inclinometers (drilling and install costs are essentially the same).

- Length of the array cannot be easily altered.

- More technical requirements for installation and operation.

- Requires special monuments to protect the data logger and other electronic equipment from environmental hazards (e.g. flooding) as well as vandalism and theft.

- Monitoring results may exhibit significant drift (as described in this paper).

There are also specific issues related to inclined holes that are discussed in Section 3.

\section{Applications}

The most common application of SAA is as an alternative to manual or in-place inclinometers. This may be as a stand-alone installation or retrofit to an existing inclinometer hole. Other geotechnical applications include:

- Buried in the crest or toe of a cutting or embankment (e.g. Dasenbrock et al. 2011).

- Placed inside a retaining wall or building (e.g. Lipscombe et al. 2014).

- Installed within a footing or pile (e.g. Pitilakis et al. 2013). 


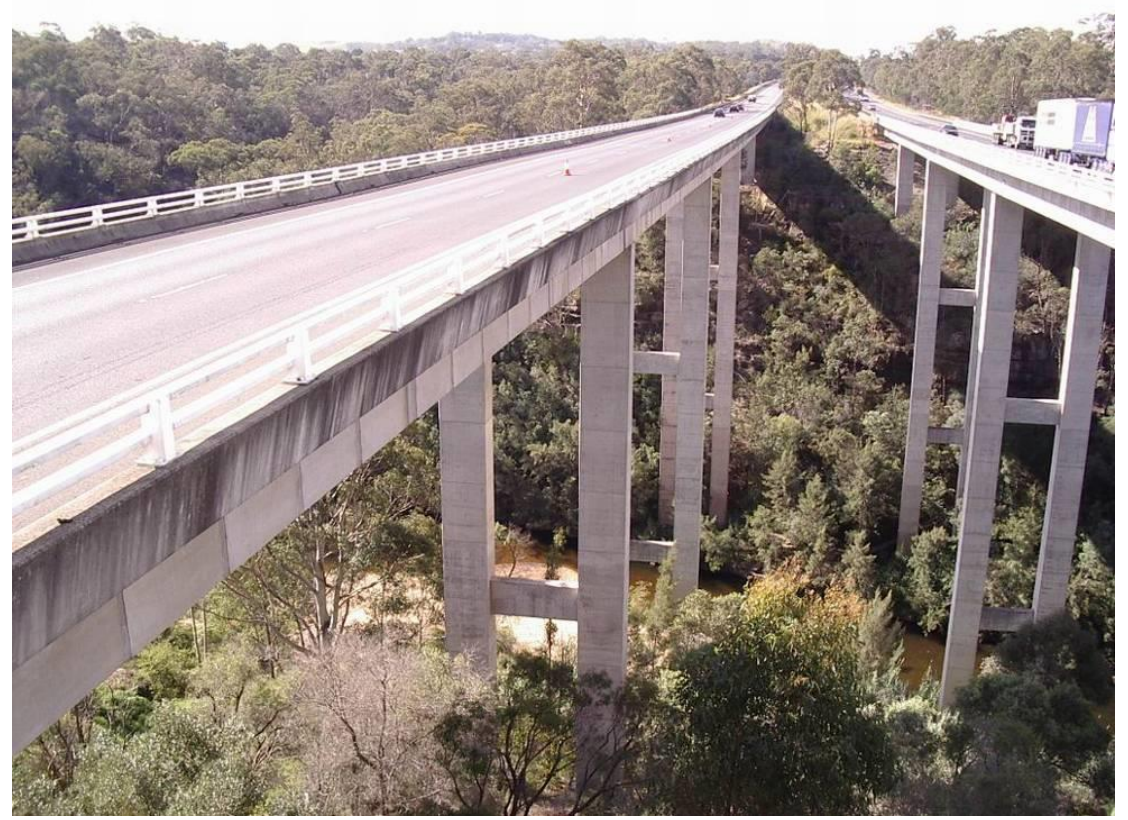

Figure 2 Douglas Park twin bridges across the Nepean River

\section{$4 \quad$ Douglas Park bridges}

The twin bridges over the Nepean River at Douglas Park were constructed in 1980 as part of the extension of the Hume Highway from Campbelltown to Yanderra. The bridges are $280 \mathrm{~m}$ long and located $68 \mathrm{~m}$ above the Nepean River (Figure 2).

Investigations undertaken since 2006 have identified a series of low angle shears zones about 20 to $30 \mathrm{~m}$ below the base of the valley floor. These shears occur with the Hawkesbury sandstone bedrock, and have been monitored since 2007 using manual inclinometers as part of the management of mining in the area.

In 2011, a new borehole was drilled to replace holes that were no longer accessible and improve the geotechnical model at the bridge site. This hole, PSM6, was inclined at $30^{\circ}$ to the vertical and sized to facilitate installation of a standard $70 \mathrm{~mm}$ inclinometer casing as well as an additional $90 \mathrm{~mm}$ plastic casing for the SAA.

The SAA installation was designed so that:

- Large deformations could be monitored without damage to the SAA instrument or it becoming stuck in the borehole.

- The array could be removed to be repaired or installed elsewhere.

The SAA needs to be housed within a $27 \mathrm{~mm}$ internal diameter PVC conduit. This diameter is important as it allows the knuckles of the array (i.e. connections between the segments) to expand under vertical load to ensure it closely conforms to the conduit geometry. Ideally, the conduit is sealed to prevent water ingress.

The system developed at Douglas Park employed neoprene transverse spacers along the length of the conduit to centralise it within the $90 \mathrm{~mm}$ plastic casing, as shown in Figure 3. The neoprene spacers were designed to provide a robust solution without resulting in undue friction which might hinder installation or removal. Additional longitudinal PVC spacers were used to position the transverse spacers. A steel cable was also attached to the base of the conduit to allow it to be removed without applying tensile force to the SAA.

The top of the SAA was housed in a heavy-duty purpose-built galvanised steel monument. A separate box was used to house the interrogator, datalogger and battery (Figure 4). 


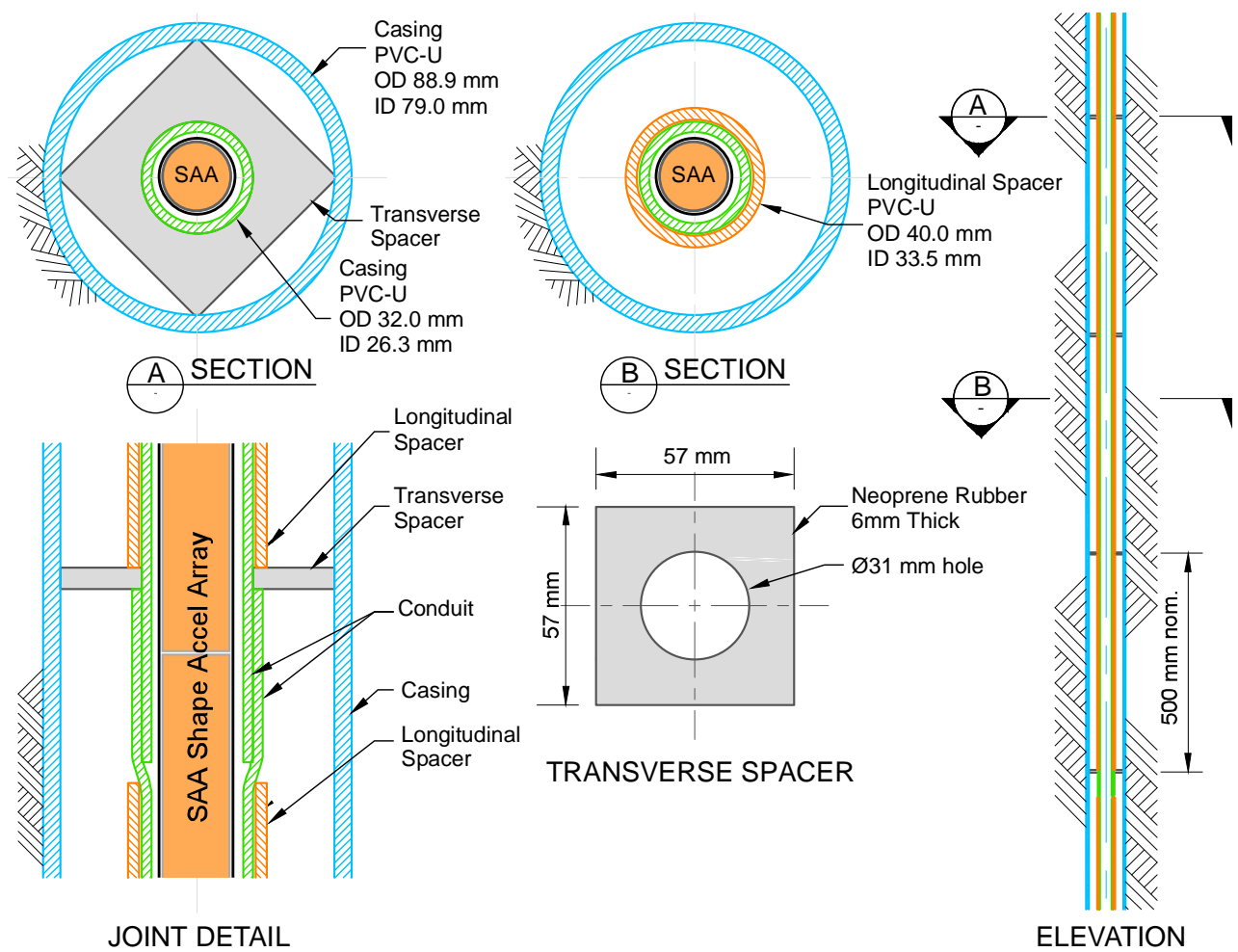

Figure 3 SAA installation employed at Douglas Park

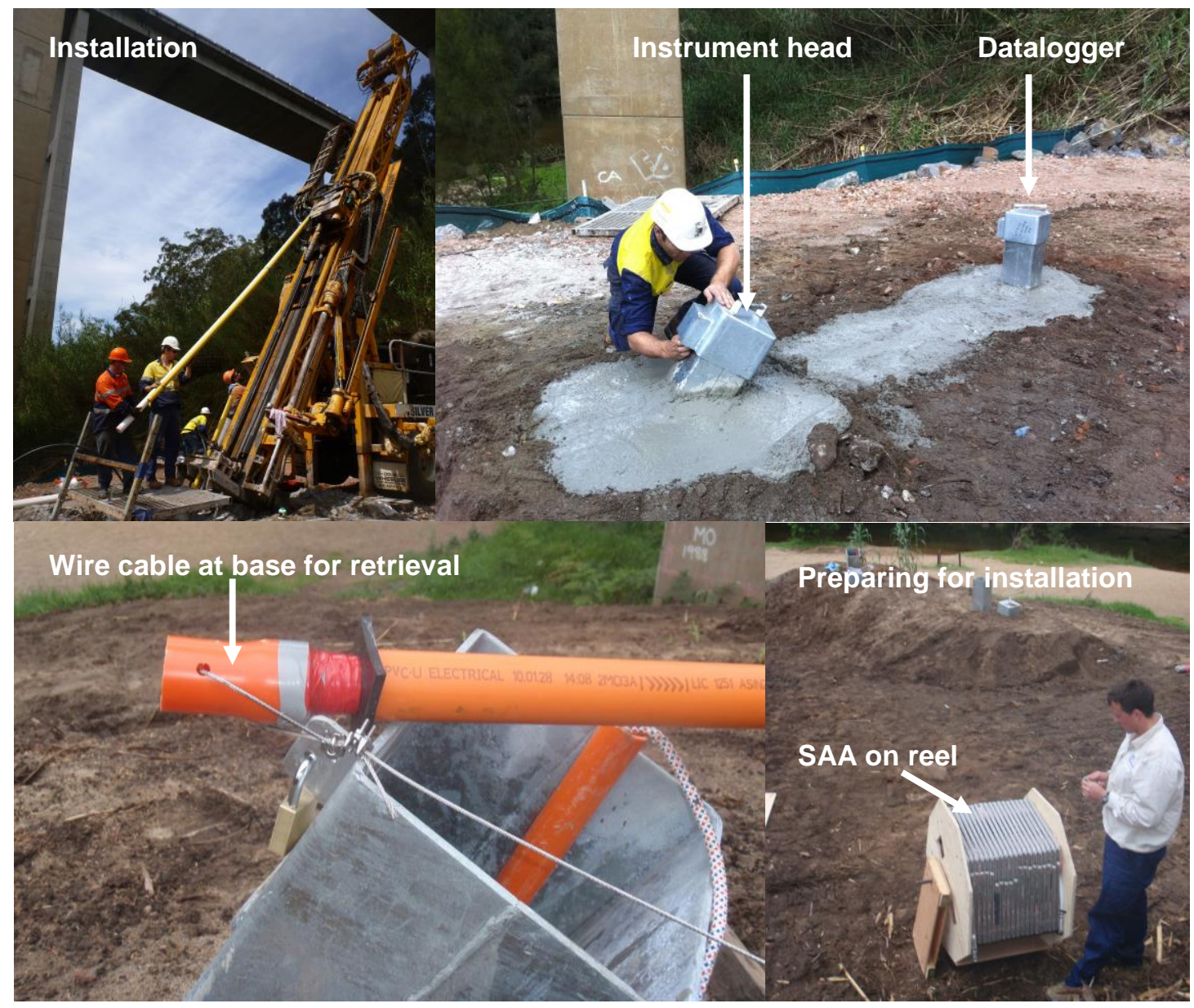

Figure 4 Drilling of borehole PSM6 and installation of the sensor array 
Following completion of the SAA installation, the instrument appeared to be functioning properly. However, within a few weeks the results suggested large movements were occurring as shown in Figure 5. After about 70 days the reported movement in the $x$ axis was around $245 \mathrm{~mm}$ in the $y$ axis was around $75 \mathrm{~mm}$. This movement was inconsistent with other survey and results from the manual inclinometer. As a further check, the top of the instrument was surveyed and confirmed not to have moved. An investigation was undertaken to assess the cause of the erroneous results.

Further assessment and analysis confirmed that the apparent movement was related to rotation of the SAA within the conduit. This was likely to have been caused by initial torsion within the array, which resulted in a gradual rotation of the array within the casing. This torsion may have been present in the instrument, or more likely was produced during installation. The MEMS accelerometers in an inclined state cannot distinguish rotation from tilt. Consequently, these changes in tilt are interpreted by the SAA as translational movement.

Other aspects of the data suggested that rotation was responsible for the apparent movement (Figure 5):

1. Magnitude of movement reduces with depth.

2. The ratio of movements in the $X$ and $Y$ axes appear to be related.

These observations are consistent with the bottom half of the array being effectively constrained by the conduit. The bottom of the array is subject to increased axial force due to the weight of the instrument, and thus greater expansion of the knuckles connecting the array segments.

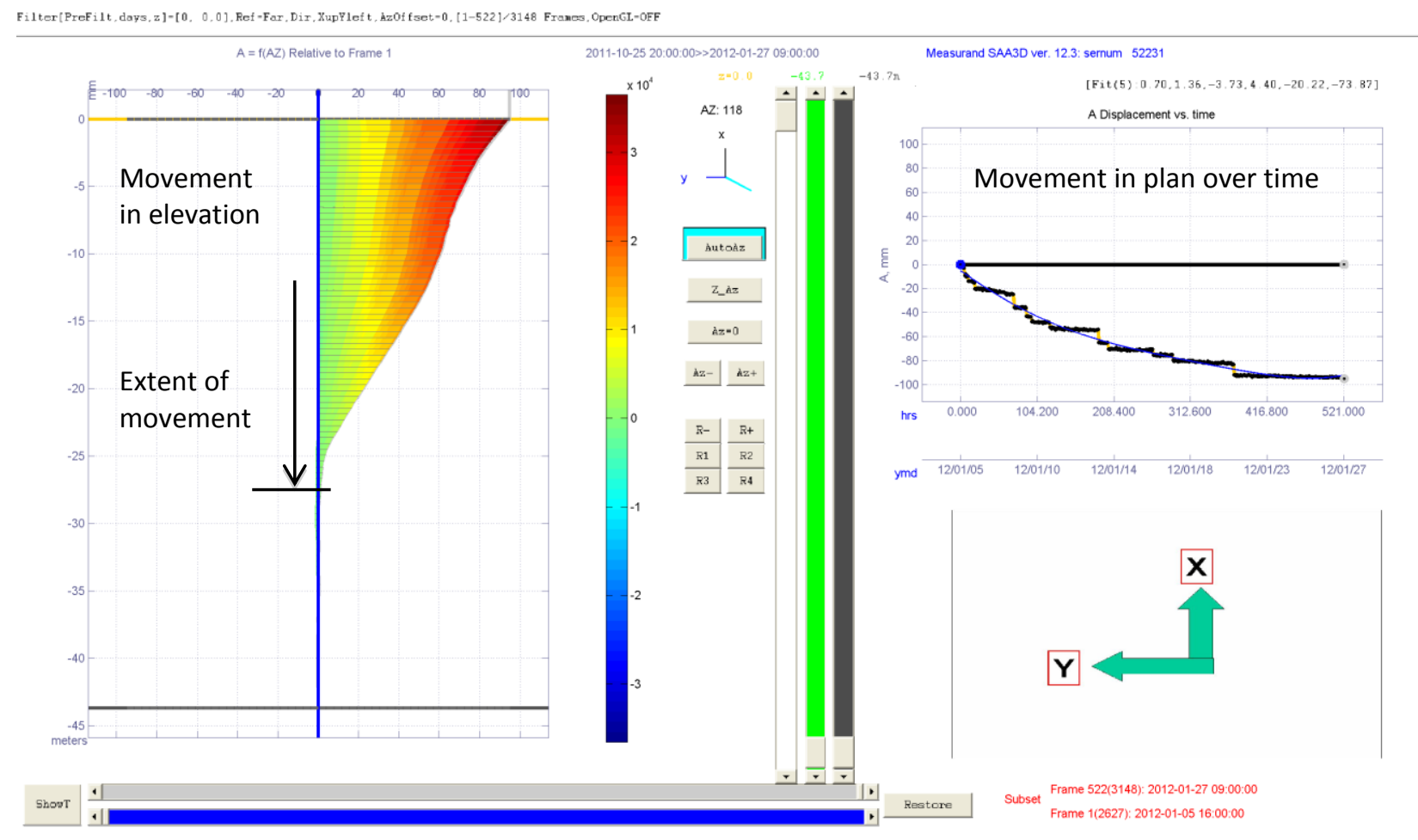

\section{Figure 5 SAA results during the initial few weeks following installation}

The suspicion that axial rotation (twist) was responsible was supported the following investigations:

- A short SAA was manually rotated when inclined and found to indicate similar apparent movements.

- A small rotation of inclined accelerometers will be interpreted as a change in tilt and therefore translation, as shown in Figure 6. 

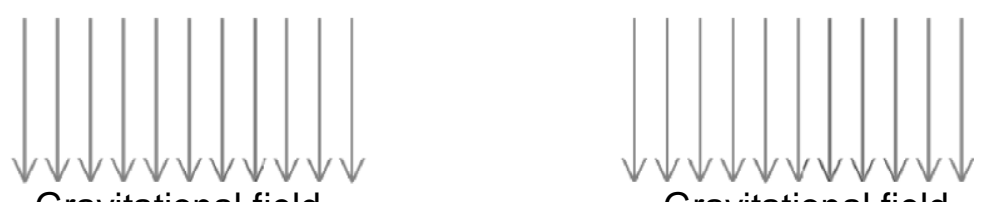

Gravitational field Gravitational field

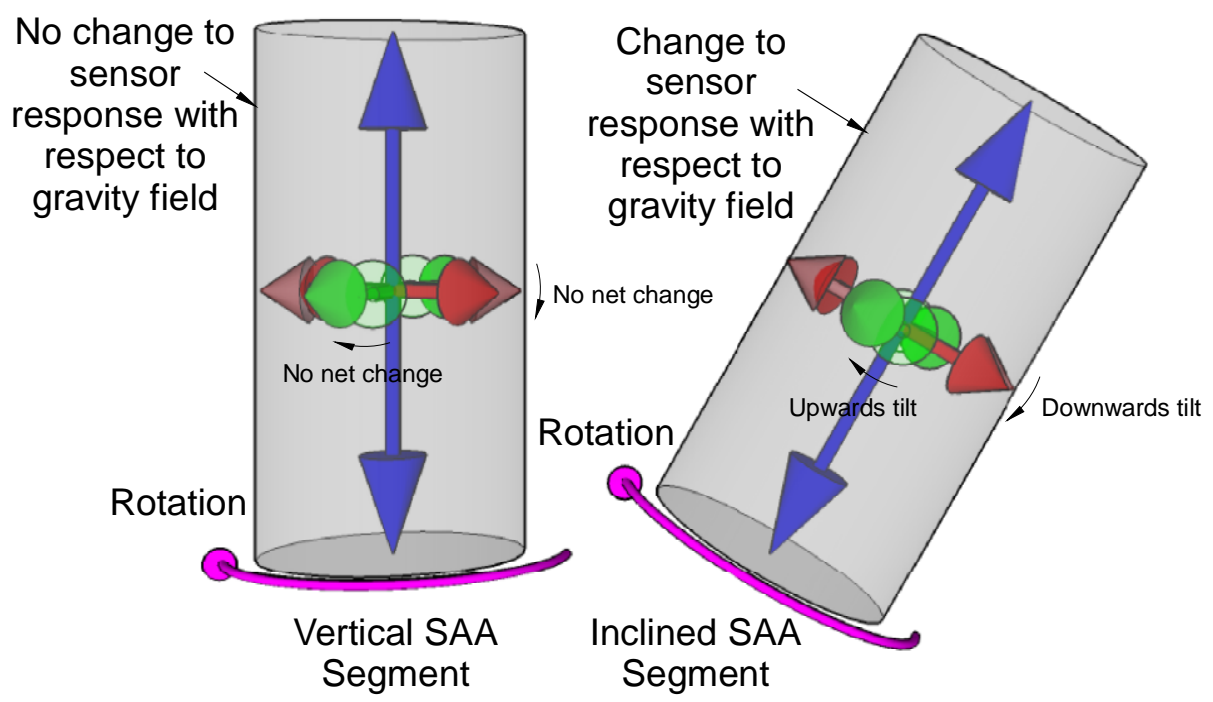

Figure 6 Schematic of vertical and inclined SAA segments subject to rotation

Figure 6 demonstrates how vertical and inclined SAA segments exposed to a uniform vertical gravity field would react to a rotation. Rotation of the vertical segment would result in all three accelerometers not registering any change in gravitational field thereby not reporting any movement. However, for the inclined case the $\mathrm{X}$ and $\mathrm{Y}$ accelerometers would experience a change in gravitational field and thereby interpret this into translational.

Further analysis was undertaken to mathematically resolve what the change in the measured gravitational field would result from an axial rotation of the SAA. This analysis derived the changes in tilts for each axis, $\psi_{x}, \psi_{y}$ and $\psi_{z}$ for each axis respectively for any given inclination angle $\theta$ and axial rotation angle $\phi$. These relationships are as follows:

$$
\begin{aligned}
& \psi_{x}=\tan ^{-1}(\sin \phi \tan \theta) \\
& \psi_{y}=\tan ^{-1}(\cos \phi \tan \theta)-\theta \\
& \psi_{x}=\phi
\end{aligned}
$$

The SAA software would convert these rotations to movements by multiplying the length of the array affected by the twist by the sine of the twist angles, $\psi_{x}, \psi_{y}$ and $\psi_{z}$.

Back analysis of the Douglas Park SAA data using the equations above found that an average axial rotation (twist) of $1.1^{\circ}$ of a SAA inclined at $30^{\circ}$ to the vertical would be sufficient to be interpreted as a $245 \mathrm{~mm}$ movement in the $X$ axis and $75 \mathrm{~mm}$ in the $Y$ axis over a length of $25 \mathrm{~m}$. These movements depend on the installation angle with respect to the $x$ axis of the device which was assessed to be $21^{\circ}$.

Further assessment was undertaken to determine the source of the twist. Possibilities are:

- The SAA was inserted into the borehole straight off the reel as opposed to the manufacturer's instructions to remove and lay straight prior to installation. The restricted site conditions adjacent to the river did not allow this to be undertaken.

- The SAA was not properly loaded on the transport reel.

- The borehole trace or spacer system resulted in a twisting of the SAA during installation. 
There is insufficient information to ascertain which of these possibilities is most likely to have caused the twist.

Since this problem was reported to Measurand the following instrument modifications have been implemented:

- There are now several twist prevention steps and warnings contained within Measurand documentation specifically warning about inducing twist during installation.

- SAAs can now include additional magnetometers that allow twist (non-alignment) to be detected and corrected 'if necessary'.

Measurand also mark SAAs with 'on reel dots' across a segment of the transport reel so that possible twist during installation on the reel can be checked.

\section{$5 \quad$ Corrective procedures}

The corrective procedure adopted to prevent or reduce the effects of untwisting was to load the SAA vertically. It was intended that such loading would promote the expansion of the knuckles engaging the SAA against the PVC conduit.

The system itself was custom built using an arrangement of slotted steel tube and springs. The system was complicated slightly in that the SAA in PSM6 is shorter than the hole and therefore the top of the SAA is located around 1,500 $\mathrm{mm}$ below the top of the PVC conduit.

The arrangement employed is shown in Figure 7 and a photo of the installed system is shown in Figure 8.
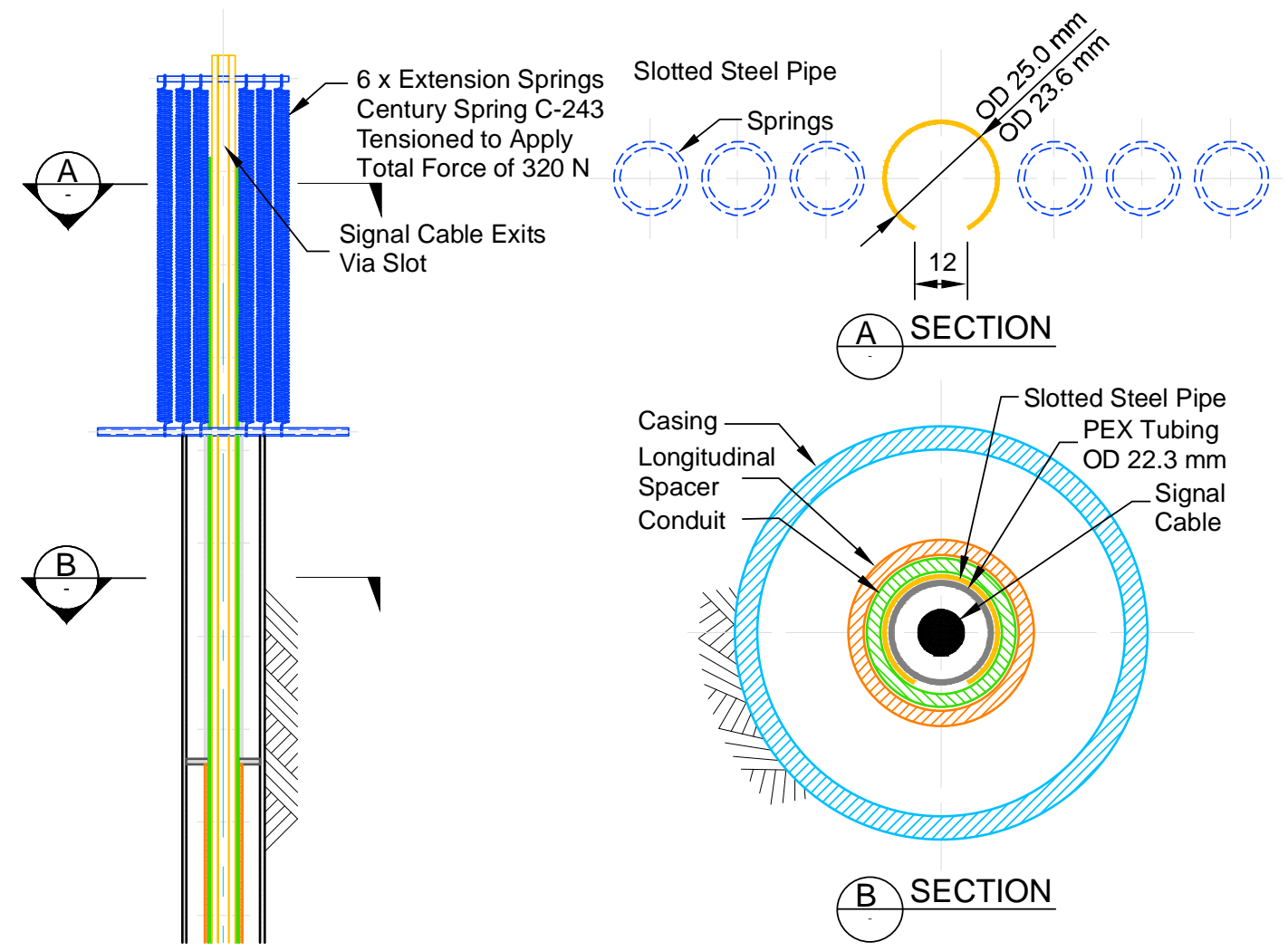

Figure 7 Diagram of vertical loading system to limit SAA rotation 


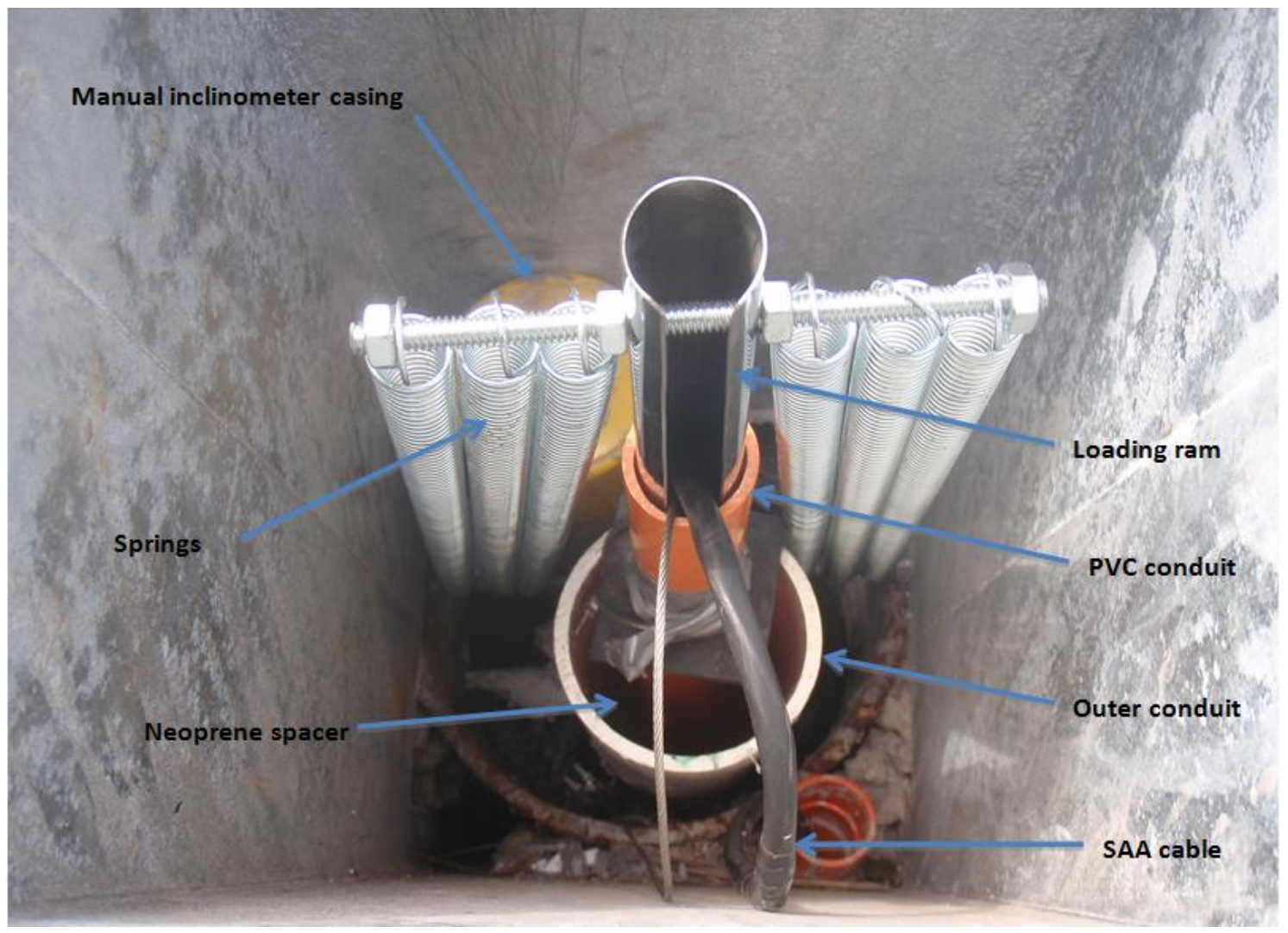

Figure 8 Photograph of vertical loading system to limit SAA rotation

\section{Instrument reliability and drift}

The Douglas Park SAA has been in continuous operation over the past four years. In that time, there have been a number of observations relating to instrument reliability and in particular drift, whereby changes in readings occur due to imperfections in the interrogation system rather than the instrument itself.

Significant drift has been observed since installation. This occurs on a reading to reading basis and can be within 1 to $2 \mathrm{~mm}$ on a daily basis and significantly more over time. A typical daily fluctuation is shown in Figure 9. This figure includes temperature readings from the uppermost thermocouple sensor in the instrument. Temperature values do not appear to change significantly over this period and therefore are not thought to be the source of drift.

Changes in readings over one year are shown in Figure 10. Movements over this period exhibit a drift of around $20 \mathrm{~mm}$ in the $x$ axis and around $10 \mathrm{~mm}$ in the $y$ axis. It is also evident that drift is accumulated over the length of the array, which mathematically has the base fixed (based on convention). By differentiating the same data readings over depth, Figure 11, much of the drift is essentially removed, and allows shear-type movements to be more readily indicated. These are most commonly the movements of interest and therefore instrument drift does not prevent this type of assessment. 


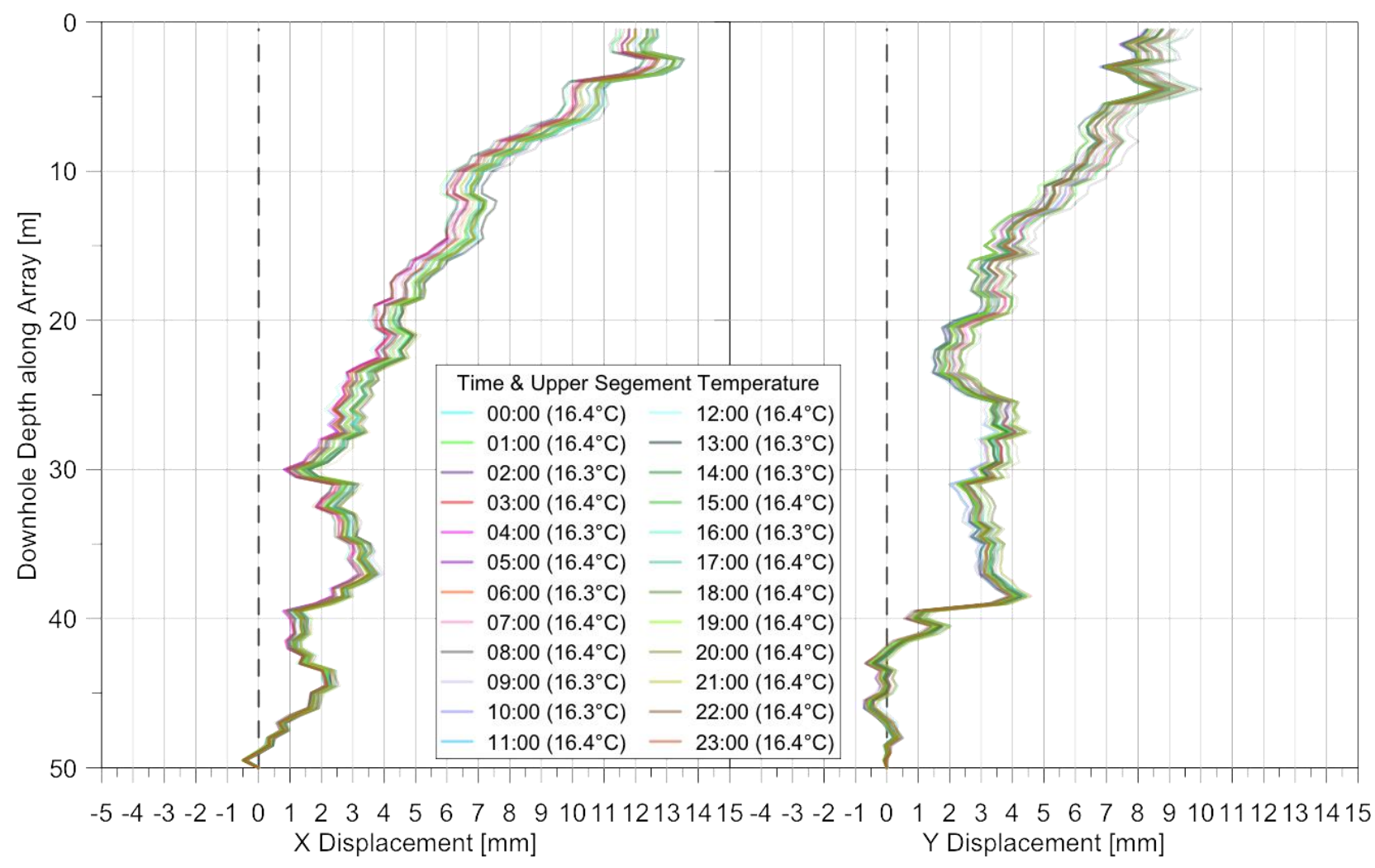

Figure 9 Typical daily drift recorded in the Douglas Park SAA

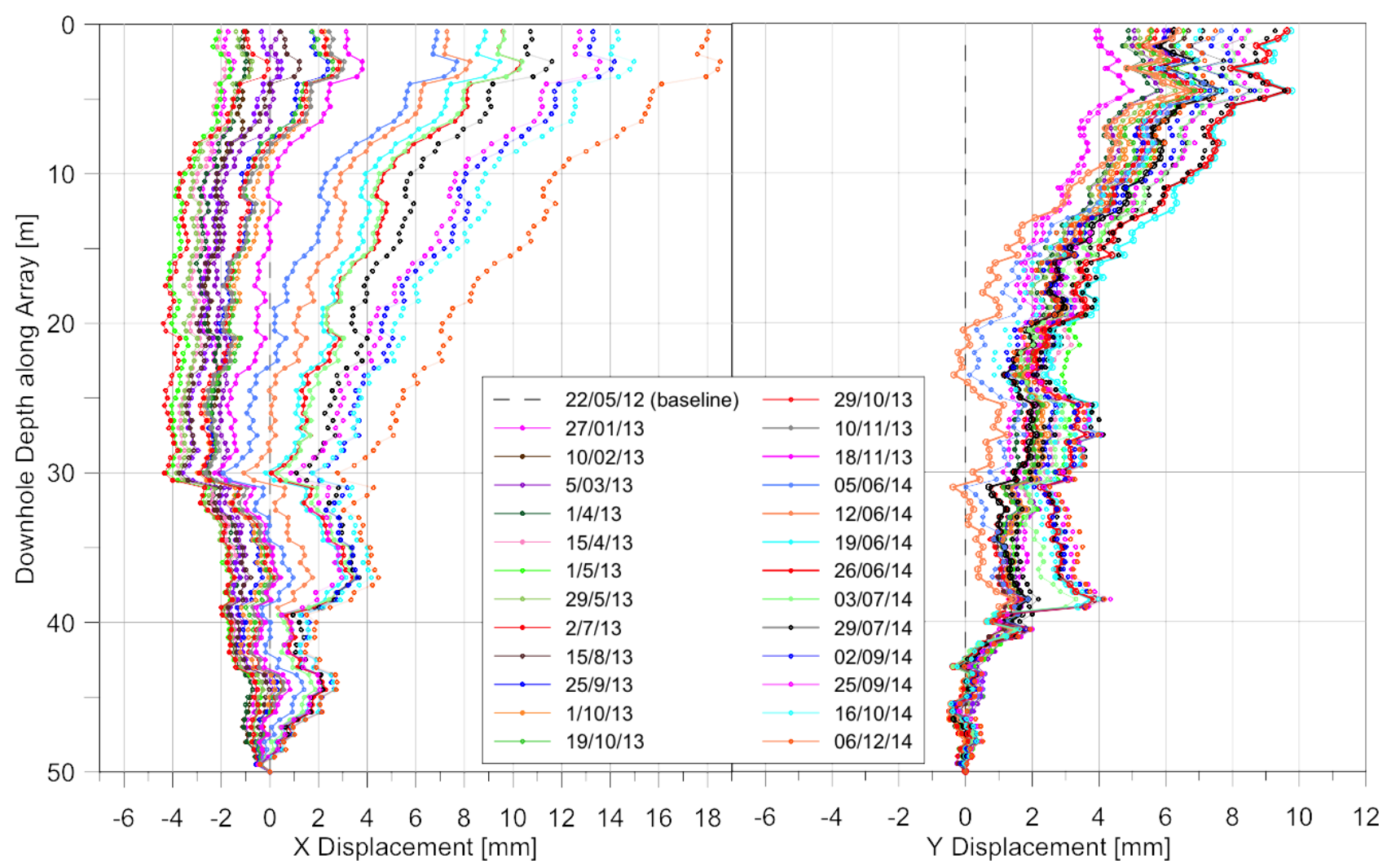

Figure 10 Movement data over one year recorded by the Douglas Park SAA 


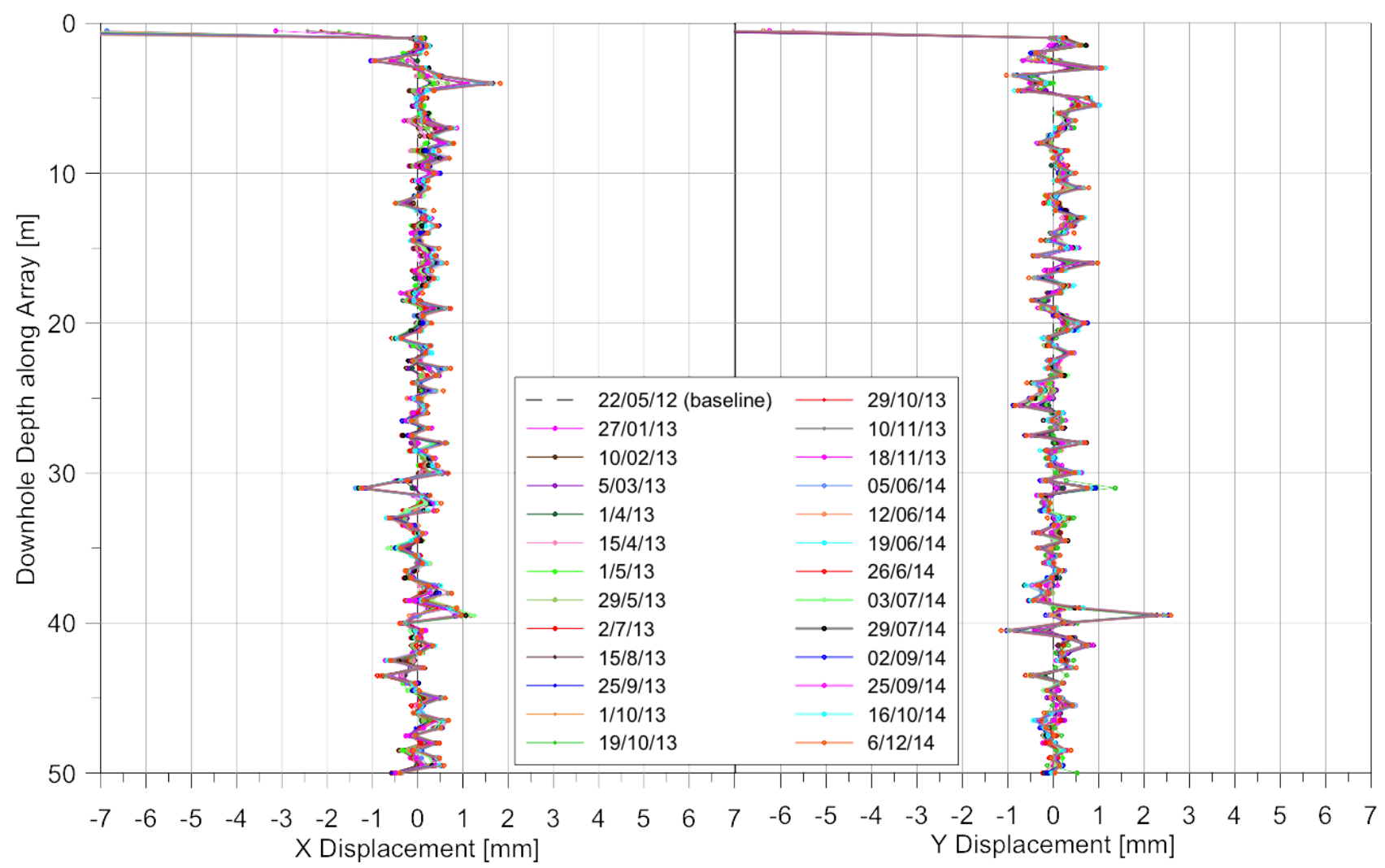

Figure 11 Differential data over one year recorded by the Douglas Park SAA

As well as drift, correct operation of the SAA depends on correct voltage of the electrical supply. Experimentation with changes in voltage found that once the SAA voltage dropped below about 10.3 volts then drift increased dramatically. It is also noted that the voltage reported by the datalogger may be significantly higher than the voltage within the SAA by up to 1 volt. More recent datalogging programs supplied by Measurand interrogate and report SAA voltage separately in recognition of the sensitivity of readings to supply voltage.

Despite the limitations described above the SAA at Douglas Park has been found to be reliable and continues to provide high frequency data that is automatically uploaded to a remote server for further assessment and analysis.

\section{$7 \quad$ Comparison with manual inclinometer data}

Currently there has been very little movement recorded by the manual inclinometer. Manual readings do suggest that there has been about 1 to $1.5 \mathrm{~mm}$ movement at a depth of around $40 \mathrm{~m}$ and about a $1 \mathrm{~mm}$ movement at a downhole depth of about $30 \mathrm{~m}$. These correspond well with the movements recorded by the SAA, Figure 10. There have been no other significant movements recorded in either system.

\section{Conclusion}

There have been a number of key lessons gained from operating the Douglas Park SAA over the past four years. These are:

- Overall, the SAA has proved to be a very useful tool for high frequency and reasonably accurate monitoring of ground movements.

- Care must be taken when installing the SAA such that twist is minimised, particularly for inclined holes. 
- If twist does occur, corrective measures can be taken to reduce the effect using vertical loading of the array.

- SAAs are prone to drift. This does not appear to be temperature related and can continue to increase over time.

- Analysis of differential movement is generally an effective means of removing drift effects and highlighting localised shear displacements.

\section{References}

Dasenbrock, D, Abdoun, T \& Bennett, V 2011, 'Real-time structural health monitoring of landslides and geotechnical assets with ShapeAccelArrays', in J Han \& DE Alzamora (eds), Proceedings of Geo-Frontiers 2011: Advances in Geotechnical Engineering, American Society of Civil Engineers, Reston, VA, pp. 1585-1594.

Hebblewhite, BK 2001, Regional horizontal movements associated with longwall mining', Proceedings of the MSTS 5th Triennial Conference on Coal Mine Subsidence, Mine Subsidence Technological Society, pp. 113-122.

Lipscombe, R, Carter, C, Perkins, O, Guerrero, S \& Thurlow, P 2014, 'The use of Shape Accel Arrays (SAAs) for measuring retaining wall deflection', Proceedings of the 39th Annual Conference on Deep Foundations, Deep Foundations Institute, Hawthorne, New Jersey, $15 \mathrm{p}$.

Pitilakis, K, Anastasiadis, A, Pitilakis, D \& Rovithis, E 2013, 'Full-scale testing of a model structure in Euroseistest to study soil-foundation-structure interaction', in M Papadrakakis, V Papadopoulos \& V Plevris (eds), Proceedings of the 4th ECCOMAS Thematic Conference on Computational Methods in Structural Dynamics and Earthquake Engineering, ECCOMAS, Barcelona pp. 1175-1188. 